We are grateful to all the hospitals that replied to the confidential questionnaire.

\section{References}

BAKer, A. A., Morrison, M., GAme, J. A. \& ThORPE, J. G. (1961) Admitting schizophrenic mothers with their babies. Lancet, ii, 237-239.

Grunebaum, H. V., Weiss, J. L., Hirsch, L. L. \& BARRETT, J. E. (1963) The baby on the ward. Psychiatry, 26, 39-53.

Kumar, R., Meltzer, E. S., Hepplewhite, R. \& STEVENSON, A. D. (1986) Admitting mentally ill mothers with their babies into psychiatric hospitals. Bulletin of the Royal College of Psychiatrists, 10, 169-172.

LUEPKER, E. T. (1972) Joint admission and evaluation of postpartum psychiatric patients and their infants. Hospital and Community Psychiatry, 23, 284-286.

MaIN, T. F. (1958) Mothers with children in a psychiatric hospital. Lancet, ii, 845-847.

TANGARI, A. (1974) Family involvement in the treatment of a psychiatric inpatient. Hospital and Community Psychiatry, 25, 792-794.

Van der Walde, P. H., Meeks, D., Grunebaum, H. V. \& Weiss, J. L. (1968) Joint admission of mothers and children to a state hospital. Archives of General Psychiatry, $18,706-711$

\title{
Why do patients occupy acute psychiatry beds? A pilot study
}

\author{
Prakash Parikh, Clinical Assistant; and Richard Stern, Consultant Psychiatrist, \\ Springfield University Hospital, 61 Glenburnie Road, London SW17 7DJ
}

The main aim of this pilot study was to identify factors influencing acute psychiatry bed use. The reasons for occupying a bed vary with time, so patients in the study were assessed on a weekly basis to monitor the changes in the factors thought to be responsible for continued stay. The reasons for bed occupancy also are often only known to those professionals directly involved in day to day care of patients, and it is suspected that the reasons often have little to do with manifest psychiatric illness. The reason for this study was to investigate this question.

\section{The study}

A census of the in-patients occupying acute admission beds in a psychiatric hospital in South London (Springfield Hospital) for three catchment area services was recorded during the ward round each week for ten consecutive weeks by a junior psychiatrist involved in the care of the patient. Information obtained included: name, hospital number, admission date, week of admission, name of consultant in charge, date of birth, sex, marital status, employment status, whether first psychiatric or first hospital admission, and whether the patient was formally detained Clinical information was obtained each week concerning psychiatric symptoms, psychiatric management, social network, involved agencies and accommodation, which were then recorded in coded form. On discharge, the disposal was recorded with total number of days in hospital. The patients present at the end of the study were followed up for discharge date and total number of days spent in hospital recorded where possible.

The study started on 22 January 1988, for two consultants' beds and after six weeks, to enlarge the sample, a third consultant's beds included. Consequently the period covered in the results is 16 weeks but occupancy status of each bed was observed for ten consecutive weeks.

Inter-rater reliability was established between the two clinicians by cross-rating ten patients during the ninth and tenth weeks of the 16 week period when minor differences were corrected.

Before the study began it was hypothesised that occupation of a bed would be for a combination of two or more of the following factors:

(a) Medical reasons for admission: meaning that the patient is in hospital to exclude or treat a medical condition; for example, he may have been admitted in a state of confusion and the possibility of a chest infection may be being investigated or treated.

(b) Psychiatric: the patient has been admitted because of a known psychiatric diagnosis. Alternatively, he is receiving a recognised psychiatric treatment in the form of medication, ECT, behaviour 
TABLE I

Total number of patients observed over ten weeks

$\begin{aligned} & \text { Patients who were admitted } \\ & \text { before the ten week period } \\ & \text { (old patients) }\end{aligned}$
$\begin{aligned} & \text { Those who came in one month } \\ & \text { before the ten week period }\end{aligned}$
$\begin{aligned} & (12 \text { in }<6 \text { months) } \\ & (9 \text { in } 6 \text { to } 12 \text { months }) \\ & (4 \text { in }>1 \text { year })\end{aligned}$

TABLE II

Demographic details of all patients

Female Single Employed Informal

\begin{tabular}{lllll}
\hline All patients & $61 \%$ & $61 \%$ & $19 \%$ & $76 \%$ \\
New patients & $64 \%$ & $46 \%$ & $23 \%$ & $80 \%$ \\
Old patients & $54 \%$ & $64 \%$ & $12 \%$ & $70 \%$ \\
\hline
\end{tabular}

TABLE III



therapy, dynamic psychotherapy, supportive psychotherapy or family therapy.

(c) Social: to provide short-term relief to the patient or others from a stressful situation. To await rehousing in ordinary accommodation. To await rehousing in a group home. To await rehousing in a hostel or old people's home. To await transfer to other NHS accommodation.

(d) Protection of others/self: the reasons for this may be fear of suicide or other deliberate self harm or violence to others, or to contain other abnormal behaviour such as self neglect, restlessness, wandering abroad.

(e) The patient has nowhere to go.

\section{Findings}

There were 85 patients in the study under three consultants' care, each observed for ten consecutive weeks; 32 patients were already admitted at the beginning of the study (old patients) and 53 patients were admitted during the study (new patients).

At the end of the study only one out of 53 new patients was still in hospital, but 19 out of 32 old patients were still in-patients; therefore the latter became a focus of interest. Table II shows some of the demographic details of the patients. Table III shows the week by week profile of the patient population, in percentages (nearest round figure approximation, of those patients already admitted at the beginning of the ten week study. (Week 1 indicates the first week of patient's stay during the study.)

The areas of employment, psychiatric symptoms and accommodation show interesting changes (Fig. 1). From $58 \%$ unemployed in the beginning of the study there is a shift to $50 \%$ at the end, which is in contrast with the employed who show an increase from $12 \%$ to $20 \%$ during the same period. Similarly the retired group show a reduction from $21 \%$ to $15 \%$ while the housewife group show an increase from $9 \%$ to $15 \%$. There was also a marked change in the psychiatric symptomatology. At the beginning of the study $18 \%$ were deemed to have no psychiatric symptoms. It should be remembered that these were patients who were already in at the beginning of the study and some had been in hospital for some time. However, by week 7 of the study $36 \%$ had no psychiatric symptoms and this was roughly maintained $(35 \%)$ at the end of ten week period. When measuring "minimal distress" this was $30 \%$ at the beginning of the study, it reached a peak at week $5(58 \%)$, and then gradually declined to $30 \%$ by the end of the study. Here it is important to note that distress is a subjective experience and the clinician must rate it by making an objective judgement. 


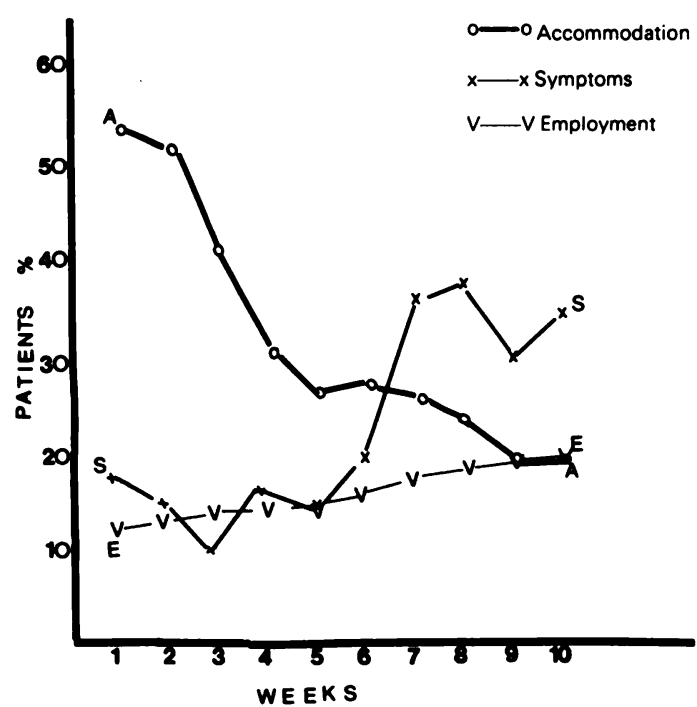

Fig. 1 Changes in accommodation, symptoms and employment.

There was nothing remarkable or unexpected about the psychiatric management during the ten weeks. As might be expected the number of patients home on leave steadily increased. The social network studied during the ten weeks showed minor fluctuations but nothing of clinical significance.

The availability of accommodation seemed to change significantly during the period of the study. For instance, there was a steady decrease in those patients who had accommodation available (Fig. 1). The percentage with accommodation available at week 1 was $54 \%$ and this gradually declined to $20 \%$. Those patients with accommodation being made found a peak at week 5 , after which this declined. There was a substantial number of patients $(33 \%)$ with no accommodation at the beginning of the study, and the percentage increased to a peak at week $8(52 \%)$ indicating that those with accommodation available had been discharged.

With these relatively small numbers it is difficult to apply statistical techniques. However, it was considered justified to examine the proportion of patients with no symptoms at week 1 compared to the same proportion at week 10 . The test showed a not quite significant difference in the proportion (s.d. $=1.67$ with two-tailed probability $P=0.0951$ ). Similarly, the proportion of patients with accommodation available at week 1 was compared to the same proportion at week 10 (s.d. $=1.89$ with two-tailed probability $P=0.059$ ). These results suggest that with larger numbers significant differences may have been found.

\section{Comment}

This survey reflects some of the factors influencing the acute bed use. It confirms the key role of relatively few patients with an extended length of stay in determining bed use, and they are an important factor in increasing acute bed requirements (Hirsch, 1983). The study also emphasises the importance of an efficient back-up service in the community; if more accommodation had been available it would probably have made a considerable difference. Fontana et al (1975) showed that symptomatology, social integration and employment each had subtly different patterns of change over a six month period following admission, similar to our study. Fenton et al (1984) reported that symptoms tended to show rapid and steady improvement while social and employment difficulties improved slowly, if at all, often leaving considerable residual disabilities even when symptoms had almost completely recovered.

Shepherd (1984) commented that "The relative integrity of outcome systems over time implies the necessity to provide services which are aimed at tackling each specific area of disabilities, and it further underlines the inadequacies of strictly medical, or symptomatic, models of care". How many beds are required for a given acute psychiatric service depends on various factors. Average bed use can only reflect demand on beds as provided and cannot accurately give indication about need (Hirsch, 1983). The Government proposes that "the number of hospital beds should be reduced only as a consequence of the development of new services" (Department of Health, 1989). The planning for beds and resources requirement must take into consideration factors affecting variations in bed use and produce estimates of bed needs and efficiency. The Working Party Report (1988) states "cutting beds without replacing them with other facilities will only serve to reduce the overall level of service to the obvious disadvantage of the patients".

This survey shows that about $98 \%$ of patients admitted during the study were discharged within ten weeks, but the patients who had already been in before the start of the study constituted $38 \%$ of total patients, of whom about $40 \%$ were in the hospital after ten weeks. It was also found that the main factor involved in their continued stay was lack of accommodation and some had lost it during their stay. When patients lose accommodation in this way it is often difficult to find a placement for them outside hospital and their stay becomes prolonged.

The employment status changed in an interesting way during the ten weeks' study. By comparing the first week with the tenth week it was seen that a higher proportion of unemployed and retired people were discharged than the employed and housewife groups, probably because the level of functional 
recovery required for the latter two groups was higher. Also perhaps alternative occupational arrangements like day hospital, day centre, sheltered workshops, and industrial therapy centre could be made more easily for the previous two groups.

This study has been limited in sample size and because of small numbers it was difficult to institute statistical techniques. Another limitation could be that negative symptoms of schizophrenia were not directly measured as such, and these symptoms could account for some of the long-stay cases. However these would be few in number in a study of an acute ward and therefore probably not influence the results. A hospital wide study with an in depth study of local services can be helpful in developing an efficient approach towards planning for beds and resources.

\section{Acknowledgements}

Ms Susan Rose helped analyse the statistical data, and Dr M. Cooke assisted in some of the data collection. The original idea for the study was put forward by the late Dr Loic Hemsi.

\section{References}

Fontana, A. F. \& Dowds, B. N. (1975) Assessing treatment outcome I. Adjustment in the community, Journal of Nervous and Mental diseases, 161, 221-230.

Fenton, F. R., Tessier, L., Struening, E. L., Smith, F. A. \& Bendr, C. (1984) Home and Hospital Psychiatric Treatment, London: Croom Helm.

Department of Health (1989) Caring for People: Community Care in the Next Decade and Beyond. $\mathrm{Cm} 849$. London: HMSO.

HIRSCH, S. R. (1983) Bed requirements for acute psychiatry units - the concept of norm. The Bulletin of the Royal College of Psychiatrists, 7, 118-122.

- (1988) Working party of the section for social and community Psychiatry of the Royal College of Psychiatrists: Psychiatric Beds and Resources: factors influencing bed use and service planning. London: Gaskell (Royal College of Psychiatrists).

SHEPHERD, G. (1984) Institutional Care and Rehabilitation. London: Longman.

\section{GASKELL $\begin{aligned} & \text { Royal College } \\ & \text { of Psychiatrists }\end{aligned}$}

\section{Contemporary Themes in Psychiatry}

\section{A Tribute to Sir Martin Roth}

Edited by

Kenneth Davison \& Alan Kerr

519 pages, $£_{20}$

ISBN 0902241281

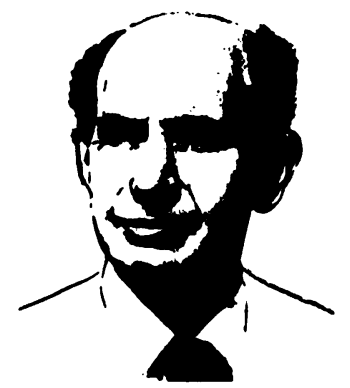

